\title{
AS QUESTÕES AMBIENTAIS E A AMBIENTALIZAÇÃO DOS CURRÍCULOS EM UMA UNIVERSIDADE: UM DIAGNÓSTICO NECESSÁRIO
}

\author{
ENVIRONMENTAL QUESTIONS AND THE CURRICULUM \\ ENVIRONMENTALIZATION IN A UNIVERSITY: A NECESSARY DIAGNOSIS
}

\author{
MARCOMIN, Fatima Elizabeti \\ fatimaelizabeti@yahoo.com.br \\ UNISUL - Universidade do Sul de Santa Catarina. \\ SILVÉRIO, Tamara Flôr \\ tamara.florsilverio@hotmail.com \\ UNISUL - Universidade do Sul de Santa Catarina. \\ SILVEIRA, Lidiane Gomes \\ lidigrb26@hotmail.com \\ UNISUL - Universidade do Sul de Santa Catarina.
}

\begin{abstract}
RESUMO O artigo é um recorte de pesquisas desenvolvidas desde 2012 e objetivou analisar se as questões ambientais e de sustentabilidade estavam contempladas em cursos de graduação da UNISUL (entre 2012-2015) e a inserção de processos de ambientalização em seus currículos. Trata-se de pesquisa qualitativa, pautada em dois sistemas de obtenção dos dados: um de cunho documental (Projetos PolíticoPedagógicos dos cursos e Planos de Ensino das disciplinas) e outro de cunho investigativo/campo (aplicação de questionários). Os resultados apontaram dificuldades de inserção da temática; os cursos de Ciências Biológicas e Agronomia foram os que mais se aproximaram de uma tentativa de ambientalização curricular; é necessário repensar a formação permanente dos professores para o aprimoramento na temática; há necessidade de deflagrar o processo na universidade em questão.
\end{abstract}

Palavras-Chave: Ambientalização. Educação Ambiental. Universidade.

ABSTRACT The article is a clipping from researches developed since 2012 that had as aim analyze whether the environmental questions and on sustainability have been contemplated in undergraduation courses at UNISUL (between 2012-2015) and the possible insertion of environmentalization processes in their curriculum. This is a qualitative research based on two systems to obtain data: a documental one (Pedagogical Project of courses and the education plan of subjects) and another investigative/field research (application of questionnaires). The results pointed to difficulties for insertion of the theme: the courses of Biological Sciences and Agronomy were closer than an attempt of curriculum environmentalization; there is the need to re-think the training process of professors in order to improve the theme; there is the need to deflagrate the process at the university in question.

keywords: Environmentalization. Environmental Education. University. 


\section{Atos de Pesquisa em Educação - ISSN 1809-0354 \\ Blumenau, v. 12, n.3, p.661-704, set./dez. 2017 \\ DOI: http://dx.doi.org/10.7867/1809-0354.2017v12n3p661-704}

\section{A TEMÁTICA}

O agravamento da problemática ambiental vem inquietando os mais diferentes setores da sociedade, disso decorrendo a necessidade de refletir e buscar soluções frente à complexidade da temática. Assim sendo, cresce a corrente pela inserção da questão ambiental e da sustentabilidade em toda a sociedade, incluindo os espaços e contextos das universidades.

Diversos estudos vêm intensificando as discussões/reflexões sobre o processo de ambientalização nas universidades. Um franco processo pela ambientalização curricular vem sendo desenvolvido no Brasil e no mundo. As universidades estão sendo chamadas a produzir, por meio de pesquisas científicas, resultados práticos em benefício da sociedade e do meio ambiente (FOLLMANN, 2014), já que as instituições são consideradas agentes dinamizadores de mudanças (RUSCHEINSKY, 2014). No Brasil, vimos destacarem-se os trabalhos desenvolvidos na Universidade Estadual Paulista (UNESP), Universidade de São Paulo (USP), Universidade Federal de São Carlos (UFSCar), Universidade do Vale do Rio dos Sinos (UNISINOS), Pontifícia Universidade Católica do Rio Grande do Sul (PUC/RS), Universidade do Vale do Itajaí (UNIVALI) e no Centro Universitário de Brusque (UNIFEBE).

A investigação dessa temática na universidade é de suma importância em função do papel que desempenha no processo formativo de sujeitos críticos, atuantes, na construção de sociedades sustentáveis, em sua responsabilidade em todos os campos e níveis de atuação universitária e no processo de ambientalização em expansão em diversas universidades (CARVALHO; CAVALARI; SANTOS SILVA, 2015; FIGUEIREDO et al., 2015; GUERRA, 2015; RUSCHEINSKY, 2014; GUERRA et al., 2014; GUERRA; FIGUEREDO, 2014a, 2014b; KITZMANN; ASMUS, 2012; ZUIN; FARIAS; FREITAS, 2009; GUERRA; ORSI, 2008; KITZMANN, 2007; SATO, 2004; ARAUJO, 2004; JUNYENT; GELI; ARBAT, 2003; GUERRA; TAGLIEBER, 2000; SORRENTINO, 1997, dentre outros). 


\section{Atos de Pesquisa em Educação - ISSN 1809-0354 \\ Blumenau, v. 12, n.3, p.661-704, set./dez. 2017 \\ DOI: http://dx.doi.org/10.7867/1809-0354.2017v12n3p661-704}

A temática da ambientalização é objeto de investigação no Programa de PósGraduação em Educação da Universidade do Sul de Santa Catarina - UNISUL, desde 2012, com subprojetos diferentes à luz de abordagens metodológicas distintas de estudo. No presente caso, o projeto objetivou analisar se as questões ambientais e de sustentabilidade são contempladas em sete cursos de graduação da citada universidade (entre 2012-2015) e a possível inserção de processos de ambientalização curricular.

\section{UM BREVE TRANSITAR PELO UNIVERSO TEÓRICO}

O interesse e preocupação com a ambientalização e a sustentabilidade nas universidades, como afirmam Guerra e Figueiredo (2014a), não são algo novo no mundo.

Não se intenciona tecer, aqui, um histórico desse processo, já que Guerra e Figueiredo (2014a, 2014b) fazem-no com muita propriedade. Destaca-se, mais recentemente, um projeto intercultural e interdisciplinar promovido pela Red ACES, em 2000, envolvendo 11 universidades, das quais seis eram latino-americanas e, destas, três eram brasileiras (Universidade Federal de São Carlos - UFScar, Universidade Estadual Paulista - UNESP e Universidade Estadual de Campinas Unicamp), cujos resultados contribuíram para intensificar as reflexões e discussões no Brasil e no estado de Santa Catarina (GUERRA; FIGUEIREDO, 2014a). Os autores destacam que redes como a Rede Sul Brasileira de Educação Ambiental (REASul) e a Aliança de Redes Ibero-americanas de Universidades para a Sustentabilidade e Ambiente (ARIUSA) vêm socializando pesquisas e experiências realizadas nas universidades brasileiras, fortalecendo o debate em torno da questão da sustentabilidade e da ambientalização nas universidades.

Para Guerra e Figueiredo (2014b), embora as Diretrizes Curriculares Nacionais para a Educação Ambiental (DCNEA) não empreguem diretamente o termo ambientalização, seu artigo 21 remete a este conceito ao estabelecer que os sistemas de ensino estimulem a constituição de espaços educadores sustentáveis. 


\section{Atos de Pesquisa em Educação - ISSN 1809-0354 \\ Blumenau, v. 12, n.3, p.661-704, set./dez. 2017 DOI: http://dx.doi.org/10.7867/1809-0354.2017v12n3p661-704}

Ambientalizar significa "inserir a dimensão socioambiental onde ela não existe ou está tratada de forma inadequada". Para a autora, é preciso considerar "[...] tanto a reforma curricular quanto a institucional, de modo a garantir a sua adequada implementação" (KITZMANN, 2007, p. 553-554).

O processo de ambientalização pode auxiliar na "[...] transição das instituições de ensino para se tornarem autênticos 'espaços educadores sustentáveis'” (GUERRA; FIGUEIREDO, 2014b, p. 116, grifo dos autores). Aliás, convém salientar que a expressão espaços educadores sustentáveis vem sendo proposta e empregada por Trajber e Sato (2010, p. 71). Ao considerar a universidade como autêntico espaço educativo sustentável, a ambientalização possibilita a inserção da sustentabilidade socioambiental, tanto na organização curricular, nos materiais didáticos e na formação de professores quanto na gestão e no fomento da cidadania, como consta no Plano Nacional de Educação (PNE 2011-2020). Dessa forma, proporciona à comunidade universitária vivência de princípios, atitudes e valores da sustentabilidade (FIGUEIREDO; GUERRA; SCHMIDT, 2012).

Ruscheinsky (2014) salienta que, para a inserção da temática ambiental nos cursos de graduação, é necessária a formação docente com competência e domínio de conteúdo. A presença de educadores interessados e informados sobre tais questões é fundamental para o sucesso na implantação da ambientalização nas Instituições de Ensino Superior (IES). O autor considera que a instituição de ensino deve ser exemplar no que faz no âmbito do ensino, pesquisa, extensão, gestão e, assim, "[...] possibilitar a multiplicação do saber adequado e proeminente para a ambientalização vigorosa e socialmente percebida como relevante" (RUSCHEINSKY, 2014, p. 121).

As dificuldades que se apresentam ao/no processo educativo, além de emperrar uma formação integradora, holística e relevadora de potencialidades dos sujeitos envolvidos, também culmina por engessar e limitar a formação dentro de compartimentos que tornam o processo desmotivador e refém de um sistema limitado e não libertador.

A ambientalização implica, necessariamente, em uma quebra de paradigma dos padrões convencionais, já que requer a inserção da temática da 


\section{Atos de Pesquisa em Educação - ISSN 1809-0354 \\ Blumenau, v. 12, n.3, p.661-704, set./dez. 2017 DOI: http://dx.doi.org/10.7867/1809-0354.2017v12n3p661-704}

sustentabilidade e, portanto, da equidade, ética, respeito e justiça para todos os sistemas, seres e estruturas do planeta e em todos os níveis e modalidades de ensino. De acordo com Zuin e Freitas (2007), o processo de ambientalização pode ocorrer, de maneira mais restrita, em apenas uma disciplina, podendo estender-se para toda a grade curricular do curso. Também pode passar pelos projetos de pesquisa e extensão e atingir toda a universidade, desde a normatização já existente até a gestão dos espaços nos quais estejam acontecendo atividades relacionadas às questões socioambientais, ou mesmo nos espaços de convivência universitária. Mesmo que iniciando timidamente, para os autores, é essencial que a universidade reveja sua política, sua estrutura e organização frente a todas as dimensões e níveis de sua atuação - gestão, pesquisa, ensino e extensão. Além de priorizar que todas as suas ações sejam espelho de gestão e práticas sustentáveis, tanto para seu âmbito interno quanto para os seres nela formados, deve estender-se para as comunidades de entorno e os demais setores por ela afetados, ou em que ela atue direta ou indiretamente.

Guerra et al. (2014) julgam necessário que o ambiente universitário seja um espaço democrático para uma reflexão crítica, para que o futuro profissional repense seu estilo de vida e objetive um consumo responsável, incorporando, em sua formação, atitudes, valores e critérios de sustentabilidade no exercício profissional como uma possibilidade para enfrentamento da crise ambiental.

\section{O MÉTODO DE ESTUDO}

A pesquisa qualitativa (ESTEBAN, 2010) pautou-se em dois sistemas distintos de obtenção dos dados: uma vertente de cunho documental por meio da análise dos Projetos Político-Pedagógicos (PPP) de cursos de graduação e dos Planos de Ensino (PE) das disciplinas; e uma vertente de cunho investigativo de campo, oriundo de um questionário semiestruturado, considerando aspectos levantados por Esteban (2010), Lüdke e André (2001), aplicado junto a 28 professores (CBI = 3; Fisio= 3; Nutri = 3; Pedag = 3; Agr = 5; Arq = 7; Geo = 4) dos cursos estudados. Nos PPP, foram estudados os itens: resumo, contextualização, objetivos, perfil de 


\section{Atos de Pesquisa em Educação - ISSN 1809-0354 \\ Blumenau, v. 12, n.3, p.661-704, set./dez. 2017 DOI: http://dx.doi.org/10.7867/1809-0354.2017v12n3p661-704}

formação (do profissional), organização didático-pedagógica, organização curricular, estrutura curricular, avaliação, articulação do ensino de graduação, condições necessárias para o fundamento do curso. Nos PE, foram analisados os itens: ementa, justificativa, objetivo, unidade programática, avaliação, referências e referências complementares, e a estrutura curricular. Os termos analisados, nos dois conjuntos de documentos (PPP e PE), foram aspectos relativos ao meio ambiente, à Educação Ambiental (EA), à sustentabilidade e ao Desenvolvimento Sustentável (DS), à qualidade de vida e à formação de valores. Esta proposição foi ajustada, também, para a análise dos questionários.

A primeira etapa da pesquisa foi realizada em 2012 e os cursos analisados foram: Ciências Biológicas, Fisioterapia, Nutrição e Pedagogia; e na segunda etapa do projeto, concluído no ano de 2014, foram investigados os cursos de Arquitetura, Agronomia e Geografia; definidos nos dois períodos a partir da disponibilidade de acesso aos documentos - com base em Deslauriers e Kérisit (2012) - respeitando amostras das licenciaturas e dos demais cursos. Em 2012, foram analisados 36 PE no curso de Ciências Biológicas, 80 no curso de Fisioterapia, 49 no curso de Nutrição e 42 no de Pedagogia; já em 2014, na segunda etapa, foram analisados quatro PE no curso de Agronomia; três no curso de Geografia; nove no curso de Arquitetura. Nos cursos de Agronomia e Arquitetura, foi adicionado o item habilidades no quadro de análise dos Planos, aspecto este não contemplado na pesquisa realizada em 2012. O total de PE analisado, nas duas pesquisas, foi de 223, nos sete cursos envolvidos no estudo, até o presente momento. Observou-se, na segunda etapa, uma redução considerável do número de PE em função de várias fases dos cursos serem oferecidas naquele momento, assim como de uma maior dificuldade de acesso a tais documentos.

A análise dos dados obtidos nos PPP e PE foi realizada por meio da construção de matrizes analíticas (documentais) adaptadas à luz das matrizes de estudo de impacto empregadas em planejamento ambiental (SANTOS, 2004). A análise dos dados, oriundos dos questionários, foi efetuada mediante a construção de categorias emergentes seguindo os critérios de Moraes (2005), marcadamente por estas assumirem, na concepção do autor, uma atitude fenomenológica, e 


\section{Atos de Pesquisa em Educação - ISSN 1809-0354 \\ Blumenau, v. 12, n.3, p.661-704, set./dez. 2017 DOI: http://dx.doi.org/10.7867/1809-0354.2017v12n3p661-704}

organizados em blocos temáticos. O cruzamento dos dados entre as matrizes analíticas e os questionários permitiu visualizar diferentes contextos envolvidos e elencar alguns aspectos para subsidiar processos de ambientalização para os cursos investigados e para a universidade. A análise e discussão dos PPP dos sete cursos foi realizada a partir da ocorrência ou não dos termos pesquisados, em que contexto isso ocorreu e com a posterior classificação: Sim (S), Não (N), Em Parte (EP). A análise dos PE ocorreu de forma individualizada para cada disciplina.

\section{RESULTADOS E DISCUSSÕES: PRINCIPAIS REFLEXÕES}

Os resultados foram organizados e discutidos em bloco: quanto ao PPP, ao PE e aos questionários.

\subsection{QUANTO AOS PROJETOS POLÍTICO-PEDAGÓGICOS (PPP)}

Quanto aos aspectos relativos ao termo meio ambiente, na análise dos PPP dos cursos envolvidos na pesquisa, constatou-se que, no curso de Ciências Biológicas ( $\mathrm{CBI}$, quadro 1), quatro itens do documento citam aspectos relativos ao termo pesquisado. Em um dos itens é abordada a formação de cidadãos comprometidos com a preservação do meio ambiente. $\mathrm{Na}$ análise do curso de Fisioterapia (Fisio, quadro 1), o termo ocorre quando aborda a questão do progresso sem limites, tendo como custo a degradação do meio ambiente. No curso de Nutrição (Nutri, quadro 1), o termo pesquisado aparece quando cita as disciplinas existentes ou em suas ementas: Saneamento Ambiental, Ecologia Ambiental, Educação em Saúde Ambiental, Saúde e Saneamento. No curso de Pedagogia (Pedag, quadro 1), aspectos relativos ao meio ambiente não foram mencionados em nenhum dos itens do projeto. A existência de disciplinas com tais temáticas não é garantia de uma abordagem crítica e emancipatória, no entanto, sugere a possibilidade para a discussão da questão; é um primeiro passo. 


\section{Atos de Pesquisa em Educação - ISSN 1809-0354 \\ Blumenau, v. 12, n.3, p.661-704, set./dez. 2017 DOI: http://dx.doi.org/10.7867/1809-0354.2017v12n3p661-704}

Quadro 1 - Aspectos levantados nos PPP dos cursos de Ciências Biológicas, Fisioterapia, Nutrição e Pedagogia em 2012

\begin{tabular}{|c|c|c|c|c|c|c|c|c|c|c|c|}
\hline \multirow{2}{*}{ Curso } & Itens pesquisados & \multicolumn{10}{|c|}{ Itens do PPP } \\
\cline { 2 - 12 } & & $\mathbf{1}$ & $\mathbf{2}$ & $\mathbf{3}$ & $\mathbf{4}$ & $\mathbf{5}$ & $\mathbf{6}$ & $\mathbf{7}$ & $\mathbf{8}$ & $\mathbf{9}$ & $\mathbf{1 0}$ \\
\hline CBI & Meio Ambiente & $\mathrm{N}$ & $\mathrm{EP}$ & $\mathrm{N}$ & - & $\mathrm{EP}$ & $\mathrm{EP}$ & - & $\mathrm{N}$ & $\mathrm{EP}$ & $\mathrm{N}$ \\
\hline CBI & EA & $\mathrm{N}$ & $\mathrm{EP}$ & $\mathrm{N}$ & - & $\mathrm{EP}$ & $\mathrm{EP}$ & - & $\mathrm{N}$ & $\mathrm{EP}$ & $\mathrm{N}$ \\
\hline CBI & $\mathrm{DS}$ & $\mathrm{N}$ & $\mathrm{EP}$ & $\mathrm{EP}$ & - & $\mathrm{N}$ & $\mathrm{S}$ & - & $\mathrm{N}$ & $\mathrm{N}$ & $\mathrm{N}$ \\
\hline CBI & Qualidade de Vida & $\mathrm{N}$ & $\mathrm{N}$ & $\mathrm{N}$ & - & $\mathrm{S}$ & $\mathrm{N}$ & - & $\mathrm{N}$ & $\mathrm{EP}$ & $\mathrm{N}$ \\
\hline CBI & Formação de Valores & $\mathrm{N}$ & $\mathrm{EP}$ & $\mathrm{S}$ & - & $\mathrm{S}$ & $\mathrm{EP}$ & - & $\mathrm{N}$ & $\mathrm{N}$ & $\mathrm{N}$ \\
\hline Fisio & Meio Ambiente & $\mathrm{N}$ & $\mathrm{N}$ & $\mathrm{N}$ & - & $\mathrm{EP}$ & $\mathrm{N}$ & - & $\mathrm{N}$ & $\mathrm{N}$ & $\mathrm{N}$ \\
\hline Fisio & $\mathrm{EA}$ & $\mathrm{N}$ & $\mathrm{N}$ & $\mathrm{N}$ & - & $\mathrm{N}$ & $\mathrm{N}$ & - & $\mathrm{N}$ & $\mathrm{N}$ & $\mathrm{N}$ \\
\hline Fisio & $\mathrm{DS}$ & $\mathrm{N}$ & $\mathrm{N}$ & $\mathrm{N}$ & - & $\mathrm{N}$ & $\mathrm{N}$ & - & $\mathrm{N}$ & $\mathrm{N}$ & $\mathrm{N}$ \\
\hline Fisio & Qualidade de Vida & $\mathrm{N}$ & $\mathrm{S}$ & $\mathrm{N}$ & - & $\mathrm{N}$ & $\mathrm{N}$ & - & $\mathrm{N}$ & $\mathrm{N}$ & $\mathrm{N}$ \\
\hline Fisio & Formação de Valores & $\mathrm{N}$ & $\mathrm{EP}$ & $\mathrm{N}$ & - & $\mathrm{S}$ & $\mathrm{N}$ & - & $\mathrm{N}$ & $\mathrm{EP}$ & $\mathrm{N}$ \\
\hline Nutri & Meio Ambiente & $\mathrm{N}$ & $\mathrm{N}$ & $\mathrm{EP}$ & - & $\mathrm{N}$ & $\mathrm{EP}$ & - & $\mathrm{N}$ & $\mathrm{N}$ & $\mathrm{N}$ \\
\hline Nutri & EA & $\mathrm{N}$ & $\mathrm{N}$ & $\mathrm{N}$ & - & $\mathrm{N}$ & $\mathrm{N}$ & - & $\mathrm{N}$ & $\mathrm{N}$ & $\mathrm{N}$ \\
\hline Nutri & $\mathrm{DS}$ & $\mathrm{N}$ & $\mathrm{N}$ & $\mathrm{N}$ & - & $\mathrm{N}$ & $\mathrm{N}$ & - & $\mathrm{N}$ & $\mathrm{N}$ & $\mathrm{N}$ \\
\hline Nutri & Qualidade de Vida & $\mathrm{N}$ & $\mathrm{S}$ & $\mathrm{N}$ & - & $\mathrm{N}$ & $\mathrm{EP}$ & - & $\mathrm{N}$ & $\mathrm{EP}$ & $\mathrm{N}$ \\
\hline Nutri & Formação de Valores & $\mathrm{N}$ & $\mathrm{S}$ & $\mathrm{S}$ & - & $\mathrm{S}$ & $\mathrm{S}$ & - & $\mathrm{EP}$ & $\mathrm{EP}$ & $\mathrm{N}$ \\
\hline Pedag & Meio Ambiente & $\mathrm{N}$ & $\mathrm{N}$ & $\mathrm{N}$ & - & $\mathrm{N}$ & $\mathrm{N}$ & - & $\mathrm{N}$ & $\mathrm{N}$ & $\mathrm{N}$ \\
\hline Pedag & EA & $\mathrm{N}$ & $\mathrm{N}$ & $\mathrm{N}$ & - & $\mathrm{N}$ & $\mathrm{N}$ & - & $\mathrm{N}$ & $\mathrm{N}$ & $\mathrm{N}$ \\
\hline Pedag & $\mathrm{DS}$ & $\mathrm{N}$ & $\mathrm{N}$ & $\mathrm{N}$ & - & $\mathrm{EP}$ & $\mathrm{EP}$ & - & $\mathrm{N}$ & $\mathrm{N}$ & $\mathrm{N}$ \\
\hline Pedag & Qualidade de Vida & $\mathrm{N}$ & $\mathrm{N}$ & $\mathrm{N}$ & - & $\mathrm{N}$ & $\mathrm{N}$ & - & $\mathrm{N}$ & $\mathrm{N}$ & $\mathrm{N}$ \\
\hline Pedag & Formação de Valores & $\mathrm{N}$ & $\mathrm{EP}$ & $\mathrm{EP}$ & - & $\mathrm{N}$ & $\mathrm{N}$ & - & $\mathrm{N}$ & $\mathrm{N}$ & $\mathrm{N}$ \\
\hline
\end{tabular}

Fonte: Desenvolvido pelas autoras. Legenda: 1- resumo; 2- contextualização; 3- objetivos; 4- perfil de formação (do profissional); 5- organização didático-pedagógica; 6- organização curricular; 7- estrutura curricular; 8- avaliação; 9- articulação do ensino de graduação; 10- condições necessárias para o fundamento do curso.

$\mathrm{Na}$ análise dos PPP do curso de Agronomia (Agr, quadro 2), o termo é citado em cinco dos sete itens existentes no documento em questão. Entretanto, sendo um curso que trabalha diretamente com assuntos relacionados às questões ambientais e, em face do atual afloramento de tal problemática, esperava-se que o termo fosse mais abordado ao longo do documento. O curso de Arquitetura (Arq, quadro 2) cita apenas quatro vezes esse termo. Contudo, é ressaltada a responsabilidade do futuro profissional com as questões sociais e com a qualidade do ambiente a ser construído, o que merece destaque. No curso de Geografia (Geo, quadro 2), o termo meio ambiente foi abordado indiretamente, em seis dos oito itens, quando destaca a questão da preservação dos recursos naturais e a ação antrópica no ecossistema costeiro. Isto é crítico, caso se considere que os cursos trabalham na formação de professores, profissionais que, futuramente, deverão tratar das questões ambientais com seus alunos. Guerra e Orsi (2008) chamam a atenção para as dificuldades de 


\section{Atos de Pesquisa em Educação - ISSN 1809-0354 \\ Blumenau, v. 12, n.3, p.661-704, set./dez. 2017 DOI: http://dx.doi.org/10.7867/1809-0354.2017v12n3p661-704}

tratamento das questões ambientais nos cursos de formação de professores. Não se trata apenas de ensinar sobre a natureza, mas de educar para e com a natureza para, desse modo, compreender e agir "corretamente diante dos grandes problemas das relações humanas com o ambiente" (MEDINA; SANTOS, 2008, p. 25).

Quadro 2 - Aspectos levantados nos PPP dos cursos de Agronomia, Arquitetura e Geografia em 2014.

\begin{tabular}{|c|c|c|c|c|c|c|c|c|c|c|c|}
\hline \multirow{2}{*}{ Curso } & Itens pesquisados & \multicolumn{10}{|c|}{ Itens do PPP } \\
\cline { 2 - 13 } & & $\mathbf{1}$ & $\mathbf{2}$ & $\mathbf{3}$ & $\mathbf{4}$ & $\mathbf{5}$ & $\mathbf{6}$ & $\mathbf{7}$ & $\mathbf{8}$ & $\mathbf{9}$ & $\mathbf{1 0}$ \\
\hline $\mathbf{A g r}$ & Meio Ambiente & - & EP & EP & EP & N & EP & EP & N & - & - \\
\hline Agr & EA & - & N & S & S & N & EP & N & N & - & - \\
\hline Agr & DS & - & EP & EP & EP & EP & EP & N & N & - & - \\
\hline Agr & Qualidade de Vida & - & N & N & EP & N & N & N & N & - & - \\
\hline Agr & Formação de Valores & - & N & N & N & EP & N & N & N & - & - \\
\hline Arq & Meio Ambiente & N & EP & N & EP & N & EP & N & N & EP & N \\
\hline Arq & EA & N & N & N & N & N & N & N & N & N & N \\
\hline Arq & DS & N & EP & EP & N & S & N & N & N & N & N \\
\hline Arq & Qualidade de Vida & N & N & N & EP & EP & N & N & N & N & N \\
\hline Arq & Formação de Valores & N & N & S & S & EP & N & N & N & N & N \\
\hline Geo & Meio Ambiente & - & EP & EP & EP & EP & EP & EP & N & - & N \\
\hline Geo & EA & - & N & N & N & N & EP & EP & N & - & N \\
\hline Geo & DS & - & EP & N & N & N & EP & N & N & - & N \\
\hline Geo & Qualidade de Vida & - & EP & N & N & N & N & N & N & - & N \\
\hline Geo & Formação de Valores & - & N & EP & N & N & N & N & N & - & N \\
\hline
\end{tabular}

Fonte: Das autoras. Legenda: 1- resumo; 2- contextualização; 3- objetivos; 4- perfil de formação (do profissional); 5- organização didático-pedagógica; 6- organização curricular; 7- estrutura curricular; 8avaliação; 9- articulação do ensino de graduação; 10- condições necessárias para o fundamento do curso.

Quanto aos aspectos relativos à EA, os cursos que abordam este termo em seus documentos são: Ciências Biológicas (CBI, quadro 1) e Agronomia (Agr, quadro 2). Observou-se que o curso de Ciências Biológicas trata de vários aspectos, incluindo os de cunho ambiental com trabalhos de observação da natureza e atuação na formação de profissionais comprometidos com a preservação e fiscalização do meio ambiente. Além disso, também cita duas das disciplinas existentes no curso, Educação e meio ambiente e Avaliação de impacto ambiental, e menciona os programas de extensão e projetos de pesquisa que abordam este termo. O curso de Agronomia (Agr) apenas cita o termo como um dos núcleos de pesquisa (Núcleo de Pesquisa em Educação Ambiental - NUPEA). Porém, em dois itens analisados, aponta as expressões criticidade e reflexão como relacionados à 


\section{Atos de Pesquisa em Educação - ISSN 1809-0354 \\ Blumenau, v. 12, n.3, p.661-704, set./dez. 2017 DOI: http://dx.doi.org/10.7867/1809-0354.2017v12n3p661-704}

sustentabilidade, aspectos estes comuns também à EA. Reigota (1998) considera que a EA é política, fundamentada em uma filosofia política, da ciência e da educação antitotalitária, pacifista e utópica, no sentido de exigir e chegar aos princípios básicos de justiça social, buscando uma nova aliança com a natureza através de práticas pedagógicas dialógicas.

O PPP do curso de Geografia (Geo, quadro 2) cita o termo quando menciona a linha de pesquisa existente na área e uma disciplina classificada como Certificação Complementar (CCO) chamada Meio ambiente e Educação. Esta disciplina tem o objetivo de planejar, coordenar e executar projetos em EA. É necessária uma investigação maior a respeito do projeto e da disciplina, considerada facultativa, pois o documento analisado não dispõe de mais informações. Entretanto, cabe ressaltar que as dificuldades encontradas na implantação da EA nos diversos níveis e modalidades de ensino constituem-se um desafio a ser vencido, e não exclusivo da universidade pesquisada. Os cursos de Arquitetura (Arq, quadro 2), Fisioterapia (Fisio, quadro 1), Nutrição (Nutri, quadro 1) e Pedagogia (Pedag, quadro 1) não fazem menção ao termo pesquisado. Este fato merece atenção e preocupação, pois é extremamente importante a formação de profissionais capacitados para lidar com essas questões diariamente e para questionar e buscar respostas/soluções frente às problemáticas ambientais, principalmente ao se considerar o curso de Pedagogia, que visa à formação de professores para atuação nas séries iniciais do processo educativo formal.

Quanto aos aspectos relativos ao DS e sustentabilidade, os cursos de Fisioterapia (Fisio, quadro 1) e Nutrição (Nutri, quadro 1) não abordam os termos em nenhum dos itens do PPP. Para Follmann (2014), hoje, mais do que nunca, é preciso que sejam cultivados, nos estudantes, princípios de sustentabilidade socioambiental, para que se tornem sujeitos responsáveis e comprometidos com a temática. No curso de Ciências Biológicas (CBI, quadro 1), o documento explicita que o curso deverá estimular o surgimento de uma mentalidade integradora entre ensino, pesquisa e extensão, ajustada ao DS, mas não esclarece o modus operandi disso. Na concepção de Follmann (2014), as universidades estão sendo chamadas a produzir resultados práticos em benefício da sociedade e do meio ambiente; logo, 


\section{Atos de Pesquisa em Educação - ISSN 1809-0354 \\ Blumenau, v. 12, n.3, p.661-704, set./dez. 2017 DOI: http://dx.doi.org/10.7867/1809-0354.2017v12n3p661-704}

com repercussão sobre o processo de inserção da temática ambiental. Nos PPP de Pedagogia (Pedag, quadro 1) e Geografia (Geo, quadro 2), é mencionado o empenho da universidade com uma educação comprometida com o DS e com a formação de cidadãos. Embora esse aspecto seja enfatizado na missão da universidade e, portanto, incorporado à missão do curso, não tece maiores explicações sobre a questão da sustentabilidade dentro do curso.

Os aspectos relativos à sustentabilidade e DS são recorrentes no documento do curso de Agronomia (Agr, quadro 2), em cinco dos sete itens, no qual consta que o curso tem como finalidade formar agrônomos comprometidos com o DS, além da importante contribuição do engenheiro agrônomo para o desenvolvimento regional sustentável. Todavia, não oferece esclarecimentos sobre a abordagem de $D S$ considerada, permitindo várias interpretações. Gadotti (2009) lembra que os temas da sustentabilidade e do DS estão na moda atualmente; com isso, acabam assumindo variadas conotações, sendo utilizados até para justificar o oposto do seu significado original. No PPP do curso de Arquitetura (Arq, quadro 2), é enfatizado que o profissional deve ser apto a utilizar soluções criativas e sustentáveis para solucionar os problemas da sociedade, mas não tece maiores detalhes acerca disso.

Para Souza e Bôlla (2012), é essencial olhar para as cidades, onde há grandes desafios socioambientais, e apresentar alternativas para que se tornem sustentáveis. Para a ocorrência da sustentabilidade é necessária uma visão holística dos sistemas do planeta, com o objetivo de compreender sua complexidade e, assim, atuar na construção de um mundo ecologicamente equilibrado, socialmente justo e economicamente viável. Vale esclarecer, a exemplo de Sato (2004), Guimarães (2004) e tantos outros, que, atualmente, vem-se trabalhando mais intensamente na perspectiva da formação de sociedades sustentáveis, o que significa que a dimensão econômica é somente uma entre todas as dimensões que devem ser consideradas quando se almeja sociedades mais justas e igualitárias.

Quanto ao aspecto relativo à qualidade de vida, o único curso que não trata desta questão em seu PPP é o de Pedagogia (Pedag, quadro 1). Ruscheinsky (2010) aponta que a suposta utopia que predomina atualmente, e que vai contra a ideia de uma sociedade sustentável, é a proliferação de bens de consumo como 


\section{Atos de Pesquisa em Educação - ISSN 1809-0354 \\ Blumenau, v. 12, n.3, p.661-704, set./dez. 2017 DOI: http://dx.doi.org/10.7867/1809-0354.2017v12n3p661-704}

sinônimo de qualidade de vida e felicidade. O curso de Ciências Biológicas ( $\mathrm{CBI}$, quadro 1) apresenta indícios de preocupação com o tema, quando relata que os projetos desenvolvidos ao longo do curso podem contribuir para uma melhor qualidade de vida dos cidadãos da comunidade, propõe disponibilizar os produtos decorrentes das pesquisas para a comunidade, e que tais conhecimentos podem auxiliar na busca por soluções de problemas ambientais. O curso de Fisioterapia (Fisio, quadro 1) alerta para a importância do profissional, na recuperação do paciente, em proporcionar programas de reeducação para uma excelente qualidade de vida. No curso de Nutrição (Nutri, quadro 1), há uma preocupação com o cuidado à saúde, bem-estar e a qualidade de vida não só dos alunos, mas da comunidade. $\mathrm{O}$ curso de Agronomia (Agr, quadro 2) destaca a importância das ações dos agrônomos para que haja a melhoria da qualidade de vida da população, mas não deixa claro quais seriam essas ações.

Ainda sobre a qualidade de vida, no PPP do curso de Arquitetura (Arq, quadro 1), é mencionado o comprometimento que o futuro profissional deve ter para garantir a qualidade de vida da população, do mesmo modo como do ambiente natural a ser construído; entretanto, não explana com mais detalhes os procedimentos. Para garantir a qualidade de vida da população é fundamental que se cuide do meio ambiente no seu entorno. No entender de Souza e Milioli (2012), nas cidades, o crescimento populacional desordenado vem acompanhado pela degradação ambiental e pela exclusão social, comprometendo a qualidade e as condições de vida humana. A qualidade do meio ambiente está relacionada à preservação e conservação dos recursos naturais. O documento do curso de Geografia (Geo, quadro 2) apenas cita que a universidade em questão prioriza uma educação universitária comprometida com a qualidade de vida, mas não especifica qual a efetiva relação existente. As transformações pelas quais passa o planeta têm afetado significativamente o meio físico, biológico, político e socioambiental, trazendo comprometimento à qualidade ambiental e de vida (PHILIPPI JUNIOR; PELICIONI, 2002); questão esta que necessita ser repensada.

Quanto aos aspectos relativos à formação de valores no curso de Ciências Biológicas ( $\mathrm{CBI}$, quadro 1), a formação de valores reporta-se para além do ser 


\section{Atos de Pesquisa em Educação - ISSN 1809-0354 \\ Blumenau, v. 12, n.3, p.661-704, set./dez. 2017 DOI: http://dx.doi.org/10.7867/1809-0354.2017v12n3p661-704}

humano: ao seu entorno, com os animais e as plantas, aparecendo em quatro itens analisados. No curso de Fisioterapia (Fisio, quadro 1), percebe-se que, em três itens, há uma aliança de pensamentos sobre valores voltados à competência profissional, por exemplo, o respeito aos direitos humanos, à responsabilidade profissional, às habilidades, ao compromisso e ao conhecimento. No curso de Nutrição (Nutri, quadro 1), apenas dois itens não apresentam aspectos atinentes à formação de valores. Os demais itens do PPP mencionam esse quesito, ressaltando sempre o conhecimento, as habilidades, a ética, as atitudes e a responsabilidade. No curso de Pedagogia (Pedag, quadro 1), a maioria dos itens não apresenta aspectos relacionados à formação de valores, exceto dois deles, que apontam que o curso prioriza os valores éticos, a valorização da prática do cotidiano constituída de valores, e apresenta, também, a priorização dos valores com vistas à satisfação de clientes, bem como a ética, o compromisso, a inovação e o respeito do profissional. No curso de Agronomia (Agr, quadro 2), apenas um item no PPP menciona que o curso busca contribuir para que o futuro engenheiro agrônomo seja comprometido com a ética, mas não discorre a respeito da relação da ética para com as questões ambientais. Para Taglieber (2007, p. 70), “[...] o processo educativo tem dupla intencionalidade: a formação social dos coletivos humanos e a sua reintegração à Natureza. Isto implica não apenas a aquisição de conhecimento, mas acima de tudo, a construção de valores e atitudes [...]".

No curso de Arquitetura (Arq, quadro 2), três itens do documento analisado abordam este tema: em dois deles percebeu-se forte comprometimento na construção e no ensino de valores, alertando para que o futuro profissional evite o individualismo. Para isso, de acordo com o documento, o conhecimento adquirido na universidade precisa estar baseado na formação ética, devendo estar presente em todas as atividades e atitudes do ser humano, em que a aplicação da ciência sempre deverá ser em favor do bem-estar da sociedade. Aponta, ainda, o comprometimento com a responsabilidade social, com destaque para questões humanísticas, dentre elas, a ética. Cabe salientar que, ao se preocupar com a formação humanística, contribuirão para a formação, mesmo que indiretamente, de sujeitos cidadãos. No curso de licenciatura em Geografia (Geo, quadro 2), quando se analisam aspectos 


\section{Atos de Pesquisa em Educação - ISSN 1809-0354 \\ Blumenau, v. 12, n.3, p.661-704, set./dez. 2017 DOI: http://dx.doi.org/10.7867/1809-0354.2017v12n3p661-704}

relativos à formação de valores, apenas um item do PPP menciona que o profissional deve intervir de maneira ética na função de educar para o exercício da cidadania. Uma questão preocupante evidenciada por Taglieber (2007), na análise feita nos currículos de formação de educadores, é que a questão ambiental não foi e nem é uma preocupação.

\subsection{QUANTO AOS PLANOS DE ENSINO (PE)}

$\mathrm{Na}$ análise dos $\mathrm{PE}$, observou-se que, quanto aos aspectos referentes ao meio ambiente, os cursos de Ciências Biológicas (CBI) e Arquitetura (Arq) são os que mais abordam este tema. Embora o curso de Ciências Biológicas não use a expressão ambientalização curricular, percebe-se maior número de disciplinas que abordam as questões ambientais. Verificou-se que, no curso, há um enfoque maior das questões ambientais nas disciplinas de Educação e Meio Ambiente e Avaliação de Impacto Ambiental. No curso de Arquitetura, diversas disciplinas mostraram certa preocupação com relação às questões ambientais, quando tratam do respeito ao patrimônio ambiental, a consciência no uso dos recursos e a busca de soluções, no planejamento dos projetos, para a área energética. $\mathrm{O}$ curso de Nutrição aborda, em quatro de suas disciplinas, a questão ambiental, quando destacam os problemas da poluição ambiental, saneamento e lixo. No curso de Fisioterapia, não foi encontrada nenhuma disciplina que aborde esse aspecto.

Nos PE analisados dos cursos de Pedagogia, Geografia e Agronomia, observou-se que o tema é citado, mas sem maior aprofundamento. No curso de Pedagogia, nos planos pesquisados, apenas duas disciplinas relacionam, em parte, aspectos sobre meio ambiente. Seria de suma importância um estudo de caráter exploratório para verificar como isso vem sendo trabalhado. No curso de Geografia, dos três PE disponibilizados, nenhum deles cita o termo pesquisado; porém, em uma disciplina, assuntos referentes ao ambiente são trabalhados. É necessário investigar se tais informações estão relacionadas à problemática ambiental e em que amplitude e profundidade são tratadas. Pois, sendo estes cursos de licenciatura, é primordial que os acadêmicos tenham compreensão das questões ambientais e 


\section{Atos de Pesquisa em Educação - ISSN 1809-0354 \\ Blumenau, v. 12, n.3, p.661-704, set./dez. 2017 DOI: http://dx.doi.org/10.7867/1809-0354.2017v12n3p661-704}

construam valores e atitudes sustentáveis, conforme salientado anteriormente. No curso de Agronomia, o termo meio ambiente é pouco citado; entretanto, em algumas disciplinas, são mencionados os biomas e ecossistemas brasileiros e mundiais, assim como o manejo correto de áreas silvestres e de reflorestamento, portanto, assuntos relacionados ao termo em questão. Diante da crise ambiental, "o processo educativo não se contenta mais com apenas a transmissão de conhecimento, exige novos princípios e valores éticos, novas posturas, novas atitudes para educar o ser humano cidadão" (TAGLIEBER, 2007, p. 70). Neste sentido, a EA Crítica poderia contribuir para uma mudança de valores e atitudes, formando "sujeitos ecológicos", com capacidade de identificar e problematizar as questões socioambientais e buscar solucioná-las (CARVALHO, 2004).

Quanto aos aspectos relativos à EA, o termo não é abordado em nenhum dos PE analisados dos cursos de Agronomia, Arquitetura, Nutrição e Geografia. Porém, isso não significa que outras disciplinas desses cursos não contemplem o quesito, já que não foi possível dispor de tais informações. Com base em Sato (2004), a EA é importante em todas as áreas de ensino, não somente nas ciências, porque as relações entre natureza e a sociedade marcam e determinam o desenvolvimento de qualquer sociedade.

No curso de Ciências Biológicas, em todo o seu currículo, apenas duas matérias mencionam a EA, em que há ênfase aos conceitos, histórico e princípios da EA. Como afirma Krasilchik (1986), para que a EA atinja plenamente seus objetivos, deve-se propiciar uma base sólida de conhecimentos, desenvolvidos através do envolvimento e participação dos alunos. No curso de Fisioterapia, apenas uma disciplina ressalta esse quesito, salientando que o acadêmico vivencie a teoriaprática, e também algumas habilidades em EA. No entanto, seria interessante uma pesquisa mais avançada, de cunho investigativo, com o professor da disciplina, com vistas a esclarecer alguns pontos, pois o conhecimento e a experiência sobre o assunto abordado refletem sobre o modo de discutir tal questão, já que o plano não deixa claro como esse assunto é trabalhado em sala de aula. No curso de Pedagogia, na análise dos planos de aula, observou-se que apenas uma disciplina menciona o termo. É relevante investir no professor e no saber emergente da sua 


\section{Atos de Pesquisa em Educação - ISSN 1809-0354 \\ Blumenau, v. 12, n.3, p.661-704, set./dez. 2017 DOI: http://dx.doi.org/10.7867/1809-0354.2017v12n3p661-704}

experiência pedagógica; paradoxalmente, a profissionalização do ensino faz-se à custa deste saber experimental. Por isso, é tão importante fazer com que os professores apropriem-se dos saberes de que são portadores e que eles sejam trabalhados do ponto de vista teórico e conceitual, e isto deve estar contemplado na inserção da dimensão ambiental (NÓVOA, 1995 apud GUERRA; TAGLIEBER, 2000, p. 69-83).

Quanto aos aspectos relativos ao DS e sustentabilidade, os cursos de Ciências Biológicas e Arquitetura são os que mais abordam este quesito nos PE analisados. No curso de Ciências Biológicas, dois planos almejam a construção de uma consciência em busca do desenvolvimento de sociedades sustentáveis. Já no curso de Arquitetura, o termo é mencionado na maioria dos referidos documentos. Contudo, é necessária maior investigação para averiguar o que, de fato, é ensinado e como é abordado o termo sustentabilidade, uma vez que o referido plano não traz tal informação. Gadotti (2009) afirma que é preciso distinguir (sem separar) a educação sobre o DS da educação para o DS. Como explica o autor, é necessário ir além da discussão teórica, faz-se necessário dar o exemplo de vida sustentável, pois as crises criadas pelos seres humanos alertam, todos os dias, que eles são seres irresponsáveis. Os cursos de Nutrição e Agronomia apenas citam uma vez o termo, porém não especificam o nível de tal tratamento.

Os cursos de Fisioterapia, Geografia e Pedagogia não mencionam o termo DS em nenhum dos PE pesquisados. Na concepção de Taglieber (2007), o professor precisa estar preparado para trabalhar a dimensão ambiental na educação e, assim, responder a problemas ambientais da sociedade. Para Costa (2002), as universidades brasileiras têm investido pouco na formação dos alunos de graduação para assumirem a inserção da EA em suas práticas profissionais.

Quanto aos aspectos relativos à qualidade de vida, os PE analisados dos cursos de Arquitetura e Geografia, não mencionam sobre este tema. Tal quesito é citado somente uma vez, de maneira muito superficial, nos cursos de Agronomia e Pedagogia. No curso de Ciências Biológicas, há duas disciplinas que envolvem o termo qualidade de vida em seu plano de aula. No curso de Fisioterapia, há seis disciplinas que abordam este quesito e enfatizam que todos os profissionais da 


\section{Atos de Pesquisa em Educação - ISSN 1809-0354 \\ Blumenau, v. 12, n.3, p.661-704, set./dez. 2017 DOI: http://dx.doi.org/10.7867/1809-0354.2017v12n3p661-704}

saúde têm o compromisso com o restabelecimento da saúde e a melhoria da qualidade de vida do ser humano, sendo necessário o entendimento do processo saúde-doença. E salienta-se que as disciplinas disponibilizarão um conhecimento aprofundado para prevenir e tratar disfunções, proporcionando melhor qualidade de vida e bem-estar. No curso de Nutrição, existem onze disciplinas que abordam o quesito, refletindo sobre a saúde do ponto de vista de alimentação/nutrição e em relação a reconhecer alguns transtornos alimentares, aplicação de tratamento adequado e, como consequência, melhor qualidade de vida ao paciente. Destaca o papel do nutricionista como agente modificador da qualidade de vida dos indivíduos para melhor e aponta que a disciplina procura estabelecer relações entre saneamento ambiental e condições de saúde do indivíduo, propondo soluções à população e visando a uma melhoria da qualidade de vida. Os cursos de Nutrição e Fisioterapia são inteiramente ligados à saúde, objetivando sempre a qualidade de vida do paciente. Porém, como enfatiza Costa (2001), as alterações de qualidade de vida vêm sendo relacionadas, cada vez mais, com alterações da qualidade do ambiente, pois alterações neste último comprometem a qualidade de vida socioambiental. Quanto aos aspectos relativos à formação de valores, de acordo com a análise dos PE, no curso de Ciências Biológicas, encontram-se três disciplinas que englobam o tema, que tratam sobre valores, como ética, cidadania, responsabilidade e respeito integrados ao meio ambiente. No curso de Fisioterapia, observou-se que o termo qualidade de vida é mencionado quando é frisada a importância dos acadêmicos promoverem a ética no cuidado com o ser humano; explicita os desafios sobre a prevenção de doenças visando sempre à assistência integral à saúde com compromisso e responsabilidade, respeitando os princípios técnicos éticos e humanos dos indivíduos sob seus cuidados. No curso de Nutrição, há uma disciplina chamada Ética e Bioética: como é de se imaginar, foca nos valores ligados à ética na saúde. No curso de Pedagogia, apenas uma disciplina trata da formação de valores, a qual viabiliza a responsabilidade dos acadêmicos em articular atividades pedagógicas. Tratando-se de um curso de formação de educadores, é crucial rever tal condição, já que à educação compete, também, a 


\section{Atos de Pesquisa em Educação - ISSN 1809-0354 \\ Blumenau, v. 12, n.3, p.661-704, set./dez. 2017 DOI: http://dx.doi.org/10.7867/1809-0354.2017v12n3p661-704}

formação de seres humanos dotados de valores éticos e morais frente à sociedade que se apresenta.

Nos PE analisados dos cursos de Agronomia, Arquitetura e Geografia, nenhuma disciplina pesquisada aborda aspectos relativos ao termo. Para Silva e Taglieber (2007), a educação tradicional faz descaso de valores importantes, e o ensino acaba tornando-se apenas memorização, transmissão da informação, de conhecimento fragmentado. Para os autores, os professores de todas as áreas de conhecimento devem refletir sobre a formação profissional em suas várias dimensões, indo além do conteúdo programático de sua disciplina, defendendo uma nova política educativa.

\subsection{QUANTO AOS QUESTIONÁRIOS}

Com relação a englobar aspectos atinentes às questões ambientais em suas disciplinas, observou-se que os professores que mais enfocaram tais questões foram os de Ciências Biológicas e Agronomia, e uma ausência nos cursos de Fisioterapia e Nutrição; e em menor expressão do tratamento deste tema no curso de Geografia. Neste último caso, cabe ressaltar que os graduandos em licenciatura, futuros professores da Educação Básica, atuarão em uma área relacionada às ciências naturais e que estuda a relação da sociedade com o meio ambiente. Logo, a inclusão das questões ambientais nesse curso é de extrema relevância. O modo humano de afetar a paisagem decorre também do modo de percebê-la, e ela é influenciada pela relação que as pessoas estabelecem com o ambiente.

No curso de Arquitetura, dos sete entrevistados, três relacionam os aspectos ambientais apenas quando é necessária a análise das condições do solo, de umidade, do vento e da iluminação na elaboração de um projeto arquitetônico ou para buscar conforto térmico e visual. Dois dos professores pesquisados destacaram a arquitetura sustentável, com o reuso da água e energia renovável no processo construtivo. No curso de Pedagogia, dos três entrevistados, apenas um engloba, em sua prática, aspectos atinentes à questão ambiental, porém não explica como e nem quais assuntos são tratados. 


\section{Atos de Pesquisa em Educação - ISSN 1809-0354 \\ Blumenau, v. 12, n.3, p.661-704, set./dez. 2017 DOI: http://dx.doi.org/10.7867/1809-0354.2017v12n3p661-704}

Quanto à questão de englobar aspectos atinentes à $E A$, constatou-se que os cursos que mais os enfocam são Ciências Biológicas e Agronomia. No primeiro, os entrevistados englobam o tema em suas disciplinas, buscando sempre sensibilizar os alunos sobre as questões ambientais, visando à mudança de comportamento frente a ações antrópicas. No curso de Pedagogia, são abordados em alguns semestres, como eixos temáticos, assuntos como o lixo. No curso de Arquitetura, apenas dois referem-se superficialmente à questão; um explica sobre a importância do destino correto das lâmpadas e o outro com o enfoque principal nas energias renováveis. Nos cursos de Fisioterapia e Geografia, apenas um professor por curso afirma que sim. É importante lembrar que nem todos os professores do curso de Geografia participaram da pesquisa e que, no semestre de 2014/A, apenas uma turma estava sendo ofertada. Porém, isto não significa que, nas demais disciplinas ofertadas em outros semestres do curso, a EA não tenha sido abordada. Já no curso de Nutrição, nenhum dos entrevistados engloba aspectos sobre a EA em suas disciplinas.

Todos os professores dos cursos de Arquitetura, Agronomia, Geografia, Ciências Biológicas e Fisioterapia informaram considerar importante englobar os aspectos ambientais e de EA em suas disciplinas. Destes professores, um de Arquitetura e um de Agronomia sugerem que tais assuntos devam ser trabalhados de maneira transversal, permeando todas as disciplinas dos cursos superiores. Um deles acredita que deveria haver disciplinas específicas que trabalhassem esses assuntos no currículo dos cursos. Vale enfatizar que a EA vem sendo objeto de discussão acerca de sua inserção em todos os níveis e modalidades de ensino, transcendendo os limites das disciplinas. No curso de Nutrição, apenas um professor referiu que não considera importante abordar aspectos ambientais em sua disciplina, já os demais, afirmam que sim, pois alegam que é necessário para que se tenha melhor compreensão da relação do ambiente versus alimentação, apontando, também, para doenças que podem ser geradas em ambientes com condições impróprias. No curso de Pedagogia, alguns professores julgam relevante, no entanto, alegam que, para isso, é indispensável ter conhecimento sobre o assunto para poder ter envolvimento, e assim poder gerar mudanças. Já outro professor, 


\section{Atos de Pesquisa em Educação - ISSN 1809-0354 \\ Blumenau, v. 12, n.3, p.661-704, set./dez. 2017 DOI: http://dx.doi.org/10.7867/1809-0354.2017v12n3p661-704}

salienta que não, pois a questão não está ligada à grade curricular, embora reconheça que essas questões devam estar presentes em sala de aula. Observa-se que grande parte dos professores está sensibilizada a respeito da problemática ambiental, e alguns até se mobilizam para enfrentar a questão, embora não esclareçam sobre tal mobilização. No entanto, ressaltam que as práticas resultantes, na maioria das vezes, são pouco eficazes para mudar, de maneira significativa, a realidade mais ampla. Com base em Guimarães (2004), nos últimos 30 anos, a consciência para a preservação da natureza tem aumentado mundialmente, contudo, não fez com que a sociedade atual diminuísse a destruição do meio ambiente: ao contrário, vive-se em uma sociedade de risco.

Sobre se conhecem, no curso em quem trabalham, alguma disciplina ou projeto que envolva as questões ambientais e/ou de EA, verificou-se que, apenas nos cursos de Ciências Biológicas e Agronomia, todos os professores participantes da pesquisa mencionam existirem várias disciplinas que abordam as questões ambientais e/ou de EA. No curso de Ciências Biológicas, as disciplinas citadas são: Ecologia e Zoologia III; Educação e Meio Ambiente; Avaliação de Impacto Ambiental; Ecologia. No curso de Agronomia, as disciplinas são: Ecologia; Entomologia; Recursos naturais renováveis; Manejo e conservação do solo; Gestão Ambiental. Em Fisioterapia, um professor cita a disciplina Educação e Promoção em Saúde I e II, e dois não mencionam nenhuma disciplina ou projeto. No curso de Nutrição, apenas um professor participante da pesquisa cita as disciplinas: Nutrição ciclos de vida; Nutrição Saúde Coletiva I e II; Estágio e Parasito. Os outros dois nada mencionam. No curso de Pedagogia, dois citam uma disciplina (Ciências dos Anos Iniciais) e um projeto: Lixo extraordinário. Já no curso de Arquitetura, alguns não conhecem, mas a maioria dos professores afirma existir, porém, nota-se que é no âmbito do ambiente a ser construído. No curso de Geografia, metade dos professores relata não conhecer nenhum projeto ou disciplina que trate das questões ambientais, e a outra metade afirma que sim, contudo um deles não soube citar qual projeto/disciplina existe. Neste caso, seria importante, na universidade aqui analisada, maior divulgação dos cursos e grupos de pesquisa que trabalham a dimensão ambiental, com vistas a estimular a propagação dessa prática. 


\section{Atos de Pesquisa em Educação - ISSN 1809-0354 \\ Blumenau, v. 12, n.3, p.661-704, set./dez. 2017 DOI: http://dx.doi.org/10.7867/1809-0354.2017v12n3p661-704}

Sobre como definem a EA, no curso de Fisioterapia, os professores em geral relatam que é uma educação ligada à sustentabilidade, transmitindo informações sobre os recursos naturais, constituindo valores e atitudes adequados para a conservação do meio ambiente e do planeta. Já no curso de Nutrição, a linha de raciocínio é que a EA é um processo pedagógico, que promove o conhecimento do ambiente, ensinando formas de preservação e de conhecer o comportamento do ambiente, construindo valores sociais para a conservação do meio ambiente. No curso de Ciências Biológicas, todos os questionados enfatizaram o conceito como uma parte da educação que visa à conscientização dos indivíduos, voltada para a preservação do meio ambiente.

No curso de Pedagogia, os professores mencionam que é um conhecimento que oportuniza uma mudança em relação à responsabilidade com o meio ambiente, que deve ser constante e conectado à educação. Jacobi (2006) acredita que a EA deve, primeiramente, buscar a solidariedade, a igualdade e o respeito à diferença. Para o autor, a EA deve ser vista como um processo contínuo de aprendizagem, em que são valorizadas as diversas formas de conhecimento, e formar cidadãos com consciência local e planetária. Além disso, considera que a "[...] EA deve ser acima de tudo um ato político voltado para a transformação social. O seu enfoque deve buscar uma perspectiva de ação holística que relaciona o homem, a natureza e o universo, [...]", considerando que "[...] os recursos naturais se esgotam e que o principal responsável pela sua degradação, é o homem" (JACOBI, 2006, p. 430431).

Grande parte dos professores dos cursos de Arquitetura, Agronomia e Geografia, quando conceituaram o termo EA, fizeram-no como formação, saberes ou metodologias com o objetivo de poluir menos, preservar a natureza, respeitar o ambiente e animais, aprender sobre questões ambientais, minimizar impactos, entre outros. Percebe-se, portanto, a concepção de uma educação voltada para a transmissão de conhecimento de caráter informativo a respeito do meio ambiente; em nenhum momento, foi relacionada como a reflexão crítica que problematiza a realidade, com caráter transformador e emancipador, como destaca Carvalho (2004). Na concepção de Guerra et al. (2014), considera-se necessário que, ao 


\section{Atos de Pesquisa em Educação - ISSN 1809-0354 \\ Blumenau, v. 12, n.3, p.661-704, set./dez. 2017 DOI: http://dx.doi.org/10.7867/1809-0354.2017v12n3p661-704}

longo da formação acadêmica, o ambiente universitário seja espaço democrático para uma reflexão crítica, para que o futuro profissional repense seu estilo de vida e para um consumo responsável, com o objetivo de incorporar, em sua formação, atitudes, valores e critérios de sustentabilidade no exercício profissional. Assim, haverá possibilidades de enfrentar esta crise mundial.

Quanto ao que entendem sobre ambientalização de currículos nos cursos superiores, observou-se que, em média, metade dos professores dos cursos de Arquitetura e Agronomia e dois do curso de Fisioterapia definiram o tema como a inserção de EA nos currículos. No curso de Geografia, apenas um professor buscou definir o tema, os demais nada compreendem sobre ambientalização de currículos. No curso de Nutrição, somente um mencionou que é a incorporação de EA na formação de futuros profissionais. No curso de Ciências Biológicas, só um professor admitiu que não sabe a respeito do termo, já os demais, consideram que é a integração da EA nos currículos escolares como tema transversal, visando à incorporação socioambiental dos conteúdos e das estruturas educativas. Verificouse que os professores do curso de Pedagogia, embora não saibam definir, relacionam a ambientalização com questões ambientais no nível superior. Neste sentido, cabe ressaltar que a ambientalização curricular envolve, de acordo com Zuin, Farias e Freitas (2009), um processo complexo de formação de profissionais que se comprometam com o estabelecimento das melhores relações possíveis entre sociedade e natureza, assim como práticas e políticas acadêmicas de ensino, pesquisa e extensão.

$\mathrm{Na}$ concepção de Figueiredo, Guerra e Schmidt (2012), as universidades tornam-se espaços educativos sustentavéis, proporcionando, aos estudantes, a vivência de princípios, atitudes e valores da sustentabilidade.

Considerando os estudos de Kitzmann e Asmus (2012), que pontuam a ambientalização como um processo de inovação que integra temas socioambientais aos conteúdos e às práticas das instituições de ensino, observaram-se, ao longo da pesquisa, as dificuldades de assimilação prática da temática, embora com reconhecimento - por parte dos professores participantes do questionário - da importância da temática socioambiental. 


\section{Atos de Pesquisa em Educação - ISSN 1809-0354 \\ Blumenau, v. 12, n.3, p.661-704, set./dez. 2017 \\ DOI: http://dx.doi.org/10.7867/1809-0354.2017v12n3p661-704}

\section{ALGUMAS CONSIDERAÇÕES}

Pôde-se observar que, dos cursos analisados, Ciências Biológicas e Agronomia, ainda que timidamente, estão mais próximos de uma iniciativa de ambientalização curricular, pois, ao longo de sua grade, há foco em algumas disciplinas, conteúdos e projetos relacionados, direta e/ou indiretamente, a questões ambientais.

No entanto, é preciso uma investigação em um número maior de PE, já que não foram disponibilizados, para este estudo, todos os planos das disciplinas dos cursos envolvidos. Os professores dos cursos pesquisados mostram-se, ainda, pouco envolvidos com projetos na área ambiental, assim como em práticas de EA. Julga-se de fundamental importância o papel da universidade na direção de sensibilizar os coordenadores e professores de todos os cursos acerca da necessidade de incorporação das questões socioambientais e da própria EA no processo formativo de seus acadêmicos não somente para atendimento aos pressupostos legais, mas, fundamentalmente, por conta de um novo tempo na Educação Superior.

Para contribuir nesta direção, urge que sejam abordadas, em sala de aula, questões ambientais sob um viés crítico, reflexivo, ético e comprometido com um ambiente ecologicamente equilibrado, e com a perspectiva da formação de valores e práticas comprometidas com a construção de sociedades sustentáveis. É inegável a responsabilidade que as universidades possuem em contribuir para processos de ambientalização que englobem o ensino, a pesquisa, a extensão e a gestão, com vistas à formação de processos e profissionais comprometidos com a sustentabilidade socioambiental. Nessa direção, é preciso repensar os espaços/tempos de formação permanente dos professores na universidade em questão no intuito de aprimorar os conhecimentos na temática da ambientalização curricular.

Além disso, é preciso que na gestão dos cursos viabilizem-se espaços de discussão e reflexão para a reformulação dos PPP e dos PE com vistas a promover a inserção da temática da ambientalização nos âmbitos do ensino, pesquisa, 


\section{Atos de Pesquisa em Educação - ISSN 1809-0354 \\ Blumenau, v. 12, n.3, p.661-704, set./dez. 2017 \\ DOI: http://dx.doi.org/10.7867/1809-0354.2017v12n3p661-704}

extensão. Ademais, a construção de abordagens teórico-metodológicas e de processos reflexivos que incorporem a dimensão ambiental deve ser uma meta permanente e que deve dar-se em todas as frentes e contextos, contemplando a formação de valores e a sensibilidade como condição primordial à formação cidadã.

\section{FATIMA ELIZABETI MARCOMIN}

Pós-Doutora em Educação pela Universidade Federal de Mato Grosso - UFMT (2012). Doutora em Ciências, área de concentração em Ecologia e Recursos Naturais pela Universidade Federal de São Carlos - UFSCar (2002). Professora na Universidade do Sul de Santa Catarina - UNISUL no Programa de Pós-Graduação Mestrado em Educação e no curso de Licenciatura e Bacharelado em Ciências Biológicas.

\section{TAMARA FLÔR SILVÉRIO}

Especialista em Ensino de Ciências - IFSC; Especialista em Gestão Ambiental FUCAP. Licenciada em Ciências Biológicas pela Universidade do Sul de Santa Catarina - UNISUL..

\section{LIDIANE GOMES SILVEIRA}

Graduanda de Ciências Biológicas - Universidade do Sul de Santa Catarina UNISUL.

\section{REFERÊNCIAS}

ARAUJO, M. I. A universidade e a formação de professores para a Educação Ambiental. In: Rede Brasileira de Educação Ambiental. Revista Brasileira de Educação Ambiental, nov. 2004. Brasília: REBEA, p. 71-78, 2004.

CARVALHO, I. C. M. Educação ambiental: formação do sujeito ecológico. São Paulo: Cortez, 2004.

CARVALHO, L. M.; CAVALARI, R. M. F.; SANTOS SILVA, D. Ambientalização nas instituições de Ensino Superior: as teses e dissertações em Educação Ambiental desenvolvidas no Brasil. In: GUERRA, A. F. S. (org). Ambientalização e sustentabilidade nas universidades: [recurso eletrônico], subsídios, reflexões e aprendizagens. 1. ed. Dados Eletrônicos. Itajaí: UNIVALI, 2015. 


\section{Atos de Pesquisa em Educação - ISSN 1809-0354 \\ Blumenau, v. 12, n.3, p.661-704, set./dez. 2017 DOI: http://dx.doi.org/10.7867/1809-0354.2017v12n3p661-704}

COSTA, A. M. F. C. Educação Ambiental no ensino formal: necessidade de construção de caminhos metodológicos. In: PEDRINI, A. (org). O contrato social da ciência: unindo saberes na Educação ambiental. Petrópolis, RJ: Vozes, 2002. p. 137-171.

COSTA, F. A. Diversidade biológica e cultural da Amazônia. In: VIEIRA, I. C. G. (org). As ciências, o uso de recursos naturais na Amazônia e a noção de desenvolvimento sustentável: por uma interdisciplinaridade ampla. Belém: Museu Paraense Emílio Goeldi, 2001. p. 300[?]-304.

DESLAURIERS, J. P.; KÉRISIT, M. O delineamento da pesquisa qualitativa. In: POUPART, J. et. al. A pesquisa qualitativa: enfoques epistemológicos e metodológicos. 3. ed. Petrópolis, Rio Janeiro: Vozes, 2012. p. 127-153.

ESTEBAN, M. P. S. Pesquisa qualitativa em educação: fundamentos e tradições. Porto Alegre: AMGH, 2010.

FIGUEIREDO, M. L. et al. Ambientalização e sustentabilidade no Centro Universitário de Brusque: um processo em construção. Rev. Eletrônica Mestr. Educ. Ambient, v. 32, n. 2, jul./dez., p. 319-338, 2015.

FIGUEIREDO, M. L.; GUERRA, A. F. S.; SCHMIDT, E. B. Ambientalização curricular em cursos de licenciatura e na educação básica: a pesquisa e a formação inicial e continuada. In: II JORNADA IBERO-AMERICANA DA ARIUSA: COMPROMISSO DAS UNIVERSIDADES COM A AMBIENTALIZAÇÃO E SUSTENTABILIDADE, 2, Itajaí, 2012. p. 100-106. Anais... Itajaí: Univali, 2012. E-book. Disponível em: <http://www.reasul.org.br>. Acesso em: 15 abr. 2014.

FOLLMANN, J. I. Sustentabilidade socioambiental e gestão da educação superior. 297-312. In: RUSCHEINSKY, A. et al. (org). Ambientalização nas instituições de Educação Superior no Brasil: Caminhos trilhados, desafios e possibilidades. São Carlos: EESC/USP, p. 297-312, 2014.

GADOTTI, M. Educar para a sustentabilidade: uma contribuição à década da educação para o desenvolvimento sustentável. São Paulo: Editora e Livraria Instituto Paulo Freire, 2009.

GUERRA, A. F. S. (org). Ambientalização e sustentabilidade nas universidades: [recurso eletrônico], subsídios, reflexões e aprendizagens. 1. ed. Dados Eletrônicos. Itajaí: UNIVALI, 2015.

GUERRA, A. F. S. et al. A temática ambiental e a sustentabilidade nos cursos de graduação da UNIVALI: caminhos para a ambientalização curricular na universidade. Rev. Eletrônica Mestrado Educação Ambiental, v. Especial, FURG, maio, p. 121134, 2014. 


\section{Atos de Pesquisa em Educação - ISSN 1809-0354 \\ Blumenau, v. 12, n.3, p.661-704, set./dez. 2017 DOI: http://dx.doi.org/10.7867/1809-0354.2017v12n3p661-704}

GUERRA, A. F. S. G.; FIGUEIREDO, M. L. Caminhos e desafios para a ambientalização curricular nas universidades: panorama, reflexões e caminhos da tessitura do Programa Univali Sustentável. In: RUSCHEINSKY, A. et al. (org). Ambientalização nas instituições de Educação Superior no Brasil: Caminhos trilhados, desafios e possibilidades São Carlos: EESC/USP, p. 145-164, 2014a.

Ambientalização curricular na Educação Superior: desafios e perspectivas.

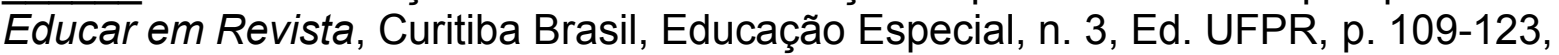
2014b.

GUERRA, A. F. S.; ORSI, R. F. M. Tendências, abordagens e caminhos trilhados no processo de formação continuada em Educação Ambiental. Rev. Eletrônica Mestrado Educação Ambiental, v. especial, FURG, dez., p. 28-45, 2008.

GUERRA, A. F. S.; TAGLIEBER, J. E. Uma reflexão sobre a dimensão ambiental na educação e as representações docentes. In: SEMINÁRIO DE PESQUISA DA REGIÃO SUL, 3, 2000, Porto Alegre. Anais... Porto Alegre: UFRGS, 2000. 15 p. 1 CD-ROM.

GUIMARÃES, M. Educação ambiental crítica. In: LAYRARGUES, P. P. (coord). Identidades da Educação Ambiental brasileira. Brasília: Ministério do Meio Ambiente, Edições MMA, 2004. p. 25-34.

JACOBI, P. Meio ambiente e Educação para a Cidadania: o que está em jogo nas grandes cidades? In: SANTOS, J. E. dos; SATO, M. (org). A contribuição da Educação Ambiental à esperança de Pandora. São Carlos: Rima, 2006. p. 423-437.

JUNYENT, M.; GELI, A. M.; ARBAT, E. Características de la ambientalización curricular: modelo ACES. In: (ed). Ambientalização curricular de los estúdios superiores. 2 Processo de caracterición de la ambientalización de los estúdio superiores. Girona: Universitad de Girona-Red ACES, v. 2. p. 15-32, 2003.

KITZMANN, D. Ambientalização de espaços educativos: aproximações conceituais e metodológicas. Rev. Eletrônica do Mestrado em Educação Ambiental, v. 18, jan./jun. p. 553-574, 2007.

KITZMANN, D.; ASMUS, M. L. Ambientalização sistêmica - do currículo ao socioambiente. Currículo sem Fronteiras, v. 12, n. 1, jan./abr. p. 269-290, 2012.

KRASILCHIK, M. Educação Ambiental na escola brasileira - passado, presente e futuro. Ciência e Cultura, v. 38, n. 12, dez. p. 1858-1961, 1986.

LÜDKE, M.; ANDRÉ, M. E. D. A. Pesquisa em educação: abordagens qualitativas. 6. ed. São Paulo: EPU, 2001. 


\section{Atos de Pesquisa em Educação - ISSN 1809-0354 \\ Blumenau, v. 12, n.3, p.661-704, set./dez. 2017 DOI: http://dx.doi.org/10.7867/1809-0354.2017v12n3p661-704}

MEDINA, N. M.; SANTOS, E. C. Educação ambiental: uma metodologia participativa de formação. Petrópolis: Vozes, 2008.

MORAES, R. Mergulhos discursivos: análise textual qualitativa entendida como processo integrado de aprender, comunicar e interferir em discursos. In: GALIAZZI, M. C.; FREITAS, J. V. (org). Metodologias emergentes de pesquisa em educação ambiental. Ijuí: UNIJUI, 2005. p. 85-114.

PHILIPPI JUNIOR, A.; PELICIONI, M. C. F. Recursos humanos em Educação Ambiental: o papel da faculdade de saúde pública da USP. In: (org). Educação ambiental: desenvolvimento de cursos e projetos. São Paulo: Universidade de São Paulo. Faculdade de Saúde Pública. NISAM: Signus Editora, 2002. p. 36-43.

REIGOTA, M. Meio ambiente e representação social. São Paulo: Cortez, 1998.

RUSCHEINSKY, A. Périplo pela incorporação da dimensão socioambiental: incertezas, desafios e tensões em trajetórias universitárias. In: RUSCHEINSKY, A. et al. (org). Ambientalização nas instituições de Educação Superior no

Brasil: Caminhos trilhados, desafios e possibilidades São Carlos: EESC/USP, 2014. p. 99-124.

Sustentabilidades: concepções, práticas e utopia. In: GUERRA, A. F. S.; FIGUEIREDO, M. L. (org). Sustentabilidades em diálogos. Itajaí: UNIVALI, 2010.

SANTOS, R. F. Planejamento ambiental. São Paulo: Oficina de Textos, 2004, 184 p.

SATO, M. Educação Ambiental. São Carlos, SP: RIMA, 2004, 66 p.

SILVA, A. M.; TAGLIEBER, J. E. A escola como centro irradiador da educação ambiental. In: GUERRA, A. F. S.; TAGLIEBER, J. E. (org). Educação Ambiental: fundamentos, práticas e desafios. Itajaí: Universidade do Vale do Itajaí, 2007. p. 197213.

SORRENTINO, M. Educação Ambiental e Universidade: um estudo de caso. In: PADUA, S. M.; TABANEZ, M. F. (org). Educação Ambiental: caminhos trilhados no Brasil. Brasília: Instituto de Pesquisas Ecológicas, 1997. p. 43-54.

SOUZA, G. C.; BÔLLA, K. D. S. Agricultura urbana com base na Agroecologia: uma nova estratégia para o desenvolvimento sustentável das cidades. In: LADWIG, N. I; SCHWALM, H. Espaço urbano sustentável: planejamento, gestão territorial, tecnologia e inovação. Florianópolis: Insular, 2012.

SOUZA, G. C.; MILIOLI, G. Limites e desafios para a sustentabilidade urbana: uma análise das condições de Criciúma, SC. In: LADWIG, N. I.; SCHWALM, H. Espaço 


\section{Atos de Pesquisa em Educação - ISSN 1809-0354 \\ Blumenau, v. 12, n.3, p.661-704, set./dez. 2017 DOI: http://dx.doi.org/10.7867/1809-0354.2017v12n3p661-704}

urbano sustentável: planejamento, gestão territorial, tecnologia e inovação. Florianópolis: Insular, 2012. p. 176-203.

TAGLIEBER, J. E. Uma pedagogia para a dimensão ambiental na educação. In: GUERRA, A. F. S.; TAGLIEBER, J. E. (org). Educação Ambiental: fundamentos, práticas e desafios. Itajaí: Universidade do Vale do Itajaí, 2007. p. 69-83.

TRAJBER, R.; SATO, M. Escolas sustentáveis: incubadoras de transformação nas comunidades. Revista Eletrônica de Educação Ambiental, v. especial, p. 70-78, set. 2010. Disponível em: <http://www.seer.furg.br/remea/article/view/3396/2054>. Acesso em: 15 fev. 2015.

ZUIN, V. G.; FARIAS, C. R.; FREITAS, D. A ambientalização curricular na formação inicial de professores de Química: considerações sobre uma experiência brasileira. Revista Electrónica de Enseñanza de las Ciencias. Vigo, v. 8, n. 2, 2009. p. 552-570.

ZUIN, V. G.; FREITAS, D. Considerações sobre a ambientalização curricular do ensino superior: o curso de licenciatura em Química. In: REUNIÃO ANUAL DA ASSOCIAÇÃO NACIONAL DE PÓS-GRADUAÇÃO E PESQUISA EM EDUCAÇÃO, 30, Caxambu. Anais... ANPED, 2007. 